\title{
Content validity of a home-based person-environment interaction assessment tool for visually impaired adults
}

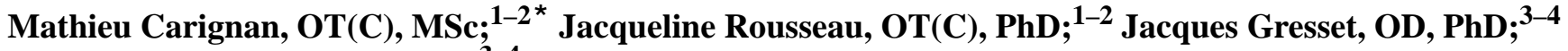 \\ Julie-Anne Couturier, MA, MSc ${ }^{3-4}$ \\ ${ }^{1}$ Rehabilitation School, Université de Montréal, Montréal, Canada; ${ }^{2}$ Research Center, Institut universitaire de \\ gériatrie de Montréal, Montréal, Canada; ${ }^{3}$ School of Optometry, Université de Montréal, Montréal, Canada; ${ }^{4}$ Center \\ for Interdisciplinary Research in Rehabilitation of Greater Montréal, Montréal, Canada
}

\begin{abstract}
Home-based assessments require in-depth analyses of daily living difficulties. No assessment tool that has been validated with visually impaired adult subjects has allowed such analysis. This research adapted a home-based personenvironment interaction assessment tool designed for persons who are visually impaired. The Model of Competence, an explanatory model of the person-environment relationship, served as the conceptual framework. A qualitative study was conducted with professionals, visually impaired persons, and informal caregivers. Focus groups and semistructured individual interviews were used for data collection. The content and form had to be modified to adapt the assessment tool for use with visually impaired adults. This qualitative study documents the content validity of the Home Assessment of Person-Environment Interaction-Visual Version. The assessment tool will provide vision rehabilitation professionals better screens and explanations of handicap-created situations faced by visually impaired persons at home. By using a structured analysis based on a personenvironment theoretical model, this new assessment tool fills a scientific and clinical gap, optimizes the evaluation process, and documents the intervention plan by providing an understanding of the home context.
\end{abstract}

Key words: activity, adult, blind, elderly, home care, low vision, model of competence, qualitative design, role, vision rehabilitation.

\section{INTRODUCTION}

The aging population will challenge the rehabilitation field because of its increasing rate of permanent impairments such as visual impairment (low vision, blindness). Expressed needs for vision rehabilitation services could double in the next 20 years [1-3]. Professionals will be greatly challenged, because visual impairment results in many functional difficulties at home [4-6]. Consequently, professionals' ability to identify and understand these difficulties will become crucial, and an evaluation of functional difficulties should precede any intervention plan.

Several authors in the field of vision rehabilitation propose that, during the evaluation process, rehabilitation professionals talk to clients to determine their goals, observe them in their environment during everyday tasks, and analyze the home and work environment to suggest specific adaptations [5,7-13]. The human environment is an

\footnotetext{
Abbreviations: $\mathrm{DCP}=$ Disability Creation Process, FG $=$ focus group, FIMBA = Functional Independence Measure for Blind Adults, HOPE = Home Assessment of PersonEnvironment Interaction, IC = informal caregiver, INLB = Institut Nazareth et Louis-Braille, O\&M = orientation and mobility specialist, OT = occupational therapist, $\mathrm{RT}=$ rehabilitation teacher, VI = visually impaired participant.

${ }^{*}$ Address all correspondence to Mathieu Carignan, OT(C), MSc; Rehabilitation School, Université de Montréal, Pavilion 7077 Park Avenue, C.P. 6128, Downtown Succ., Montréal QC, H3C 3J7 Canada; 514-343-6111, ext 17354; fax: 514-340-3548. Email: m.carignan@umontreal.ca DOI: 10.1682/JRRD.2007.10.0158
} 
important element to consider because visually impaired persons often make demands of their caregivers [14].

The assessment of a client by means of an activity, taking into consideration the environment in which it takes place, is part of an emerging perspective in the rehabilitation literature: the person-environment relationship [15-25]. In this perspective, concerned with ecological validity [25-26] (i.e., a person integrated into his or her everyday environment), the question is not whether a visually impaired person can prepare a meal but whether this person can prepare the meal he or she wants in the home kitchen, which is characterized by specific features (lighting, contrast, organization). This analysis method should prevail in vision rehabilitation [25], and home is a key environment in developing such an understanding $[16,22,27]$.

\section{Assessment Tools}

Several assessment tools have been validated with visually impaired and elderly adults [28-49], as reviewed in the literature [50-56]. These tools can be divided into two categories: environment and daily living activities. Certainly, many assessments aim to determine quality of life, but these assessments evaluate a different construct.

The few assessment tools that target the environment in vision rehabilitation are either specific to a single component, such as lighting [57] or allocation of technical devices [58-59], or very broad and include the political environment [60]. In both cases, analysis of the environment is restricted.

Assessments of daily living activities offer diverse assessment modes: questionnaire, observation, or both [28-31,33-48]. Questionnaires allow the client's perception to be included [29-31,33-34,38,41,44,46-49]. They are generally valid in this regard [61-62] but can only lead to a limited understanding of the home context because of their low ecological validity [25]. On the other hand, assessments using only observational data [28,45] can evaluate the person-environment relationship directly; however, clients' perception of their own needs is not considered.

Assessments that combine both assessment modes can be key to incorporating the perceptions of both the client and the evaluator in the daily living context. But existing assessments, such as the Functional Independence Measure for Blind Adults (FIMBA) [39-40,42], the Low Vision Functional Status Evaluation [43], and the Melbourne Low-Vision Activities of Daily Living
Index and its weighted version [35-37], have another limitation: they are not based on a conceptual framework. A conceptual framework allows the professional to group variables for a better understanding of the observed phenomenon and shows how it is interpreted [17,22,63-64]. The FIMBA in particular has no demonstrated psychometric properties other than internal consistency.

In summary, although all these instruments examine some aspects of the person-environment relationship, none allows a comprehensive and in-depth analysis of it; these assessments do not enable professionals to analyze the complex context of the home environment. Many of these instruments focus on intervention outcomes. An indepth analysis of the causes underlying a person's functional difficulties is essential for an effective intervention [17]. Moreover, psychometric properties should be one of the key elements for assessment tools [65].

\section{Person-Environment Relationship Assessment Tool for Other Populations}

Since the existing assessment tools in the vision rehabilitation field do not allow professionals to specifically understand the relationship between a person and his or her environment, assessment tools validated with other populations were reviewed. Rousseau et al. surveyed a wide range of instruments aimed at home adaptation or the person-environment relationship, and they concluded that a need existed for a new assessment tool: the Home Assessment of Person-Environment Interaction (HOPE) [22]. Since 2002, however, no other instrument has included the elements highlighted by Rousseau et al. The HOPE assessment tool, which was developed for individuals with motor disabilities, may also be applicable for use with visually impaired persons. Based on the Model of Competence, an explanatory model of the personenvironment relationship $[20,66]$, the HOPE provides a structured analysis, allowing the evaluator to better identify and understand the different personal, environmental, and interactive components of a home context [67]. The HOPE's content validity [20], test-retest reliability [68], and interrater reliability are high [69]. Its construct validity and internal consistency are under study. HOPE versions have been adapted to the pediatric population [70-71] and the elderly population with cognitive impairments [72], but no study has yet been conducted with the visually impaired population.

In spite of the growing need for home-based assessments, the vision rehabilitation literature does not highlight 
any other assessment tool developed within a personenvironment relationship perspective and including good psychometric properties. This lack may explain professionals' widespread use of homemade assessment tools. Unfortunately, homemade tools can be prejudicial to clients because of the evaluator's subjectivity [20,22,59], for example, stereotyping an intervention on the basis of the client's age and visual condition alone [59]. Therefore, a need exists for an assessment tool that will objectify the home-based evaluation process for visually impaired adults.

\section{Study Relevance}

A literature review revealed no available assessment tool that has been validated for use with visually impaired adults and that will allow professionals to both identify and explain difficulties at home from a personenvironment perspective. To objectivize the assessment process and, consequently, intervention targets, professionals must have such an assessment tool. The HOPE seems appropriate for adaptation to the visually impaired population: it considers the person-environment relationship specifically at home, is based on a conceptual framework, and has good psychometric properties. The HOPE will be described in more detail in the next section. In an initial phase, the content validity of the HOPE has to be examined regarding the visually impaired population. Content validity must be built in during the construction of a test with the right choice of items [73].

\section{Theoretical Framework}

The Model of Competence [20,27,66,74] allows an in-depth analysis of the interaction between a person and his or her environment, particularly in a home context [21]. This model gives rehabilitation professionals and researchers a way to identify and analyze unique elements that play a role in a home context and prevents an overor underestimation of the interaction misfits and, consequently, of the intervention [74]. The Model of Competence articulates six concepts: (1) person [75], (2) environment [26,74], (3) roles [77-79], (4) activities [79], (5) competence situation [66,80-81], and (6) handicap-created situation [82]. In this model, the person is considered a mind/ body unit that continuously interacts with his or her immediate environment (home), which consists of two dimensions: human and nonhuman. The understanding of this relationship focuses on congruence between the person's characteristics and the environmental resources, within the activities to be done and roles to be assumed. "Competence situation" and "handicap-created situation" are concepts qualifying the two end points of this interaction continuum. By identifying the content of the interaction between the person and the environment, this model determines the impact of impairment on activities and roles and highlights the person, environment (human and nonhuman), and interaction elements that create competence or handicap-created situations.

This model is concerned with the human environment, which is very much solicited by the visually impaired population [14]. The Figure illustrates the Model of Competence as it is used in this study.

\section{Description of HOPE}

The HOPE instrument includes six sections: (1) General Information, (2) Preliminary Tests, (3) Nonhuman Environment, (4) Human Environment, (5) Synthesis, and (6) Potential [27,67]. The General Information section documents medical and personal information within the home and occupational contexts (e.g., working at home). The Preliminary Tests section includes preliminary tests that assess any physical characteristics of the person that may be relevant to living at home (e.g., poor balance). The Nonhuman Environment section assesses the home's accessibility, indoors and outdoors, with an analysis of the interaction between the person and the nonhuman environment during activities and operations (actions) carried out in each room of the home (e.g., access to a light switch). The assessment is performed by observation of the person's operations. The Human Environment is evaluated by means of role analysis (spouse, parent), which is the interaction between the person and the human environment. Special attention is paid to the

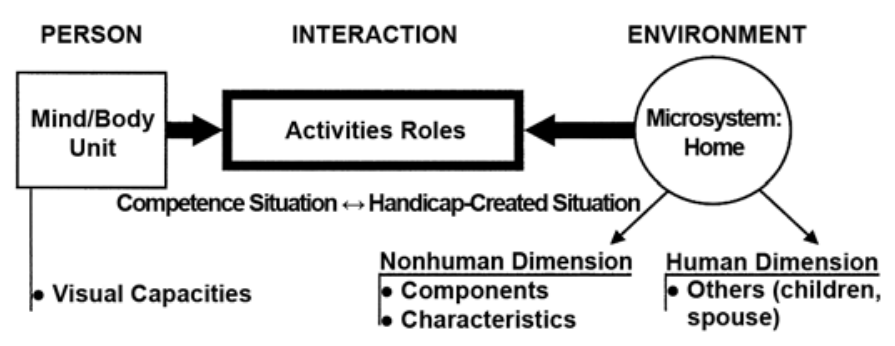

Figure.

Operationalization of the Model of Competence. Source: Adapted from Rousseau J, Potvin L, Dutil E, Falta P. A critical review of assessment tools related to home adaptation issues. Occup Ther Health Care. 2002;14(3/4):93-104. 
expectations of the person and the other people involved (human environment), as expressed through individual interviews. The Synthesis section highlights interaction problems. Finally, the Potential section is concerned with the potential for change in the person and in the human and nonhuman environments. The competence scale is used to score items on the HOPE. This scale is a fourpoint ordinal scale (3 "competence situation" to 0 "handicap-created situation") based on the Model of Competence. The HOPE is a French-language assessment tool.

\section{METHODS}

The design of this study was an instrument validation (development study) [83]. The goal was to adapt a homebased person-environment interaction assessment tool for use with the visually impaired population. The HOPE tool was initially developed for a population with motor disabilities. Two interview techniques, focus group (FG) [82] and semistructured individual interview [85-86], were used to collect the expert opinions through a qualitative approach to the assessment process and the intervention at home. Visually impaired participants (VIs), informal caregivers (ICs), and experienced vision rehabilitation professionals were interviewed.

The number of participants in each of these groups was established by data saturation [87] applied to the following research question: Do the HOPE's elements represent the limits faced at home by visually impaired adults? The study was approved by the research ethics committee of the Research Center of the Institut universitaire de gériatrie de Montréal and by the Research Ethics Board of the Center for Interdisciplinary Research in Rehabilitation of Greater Montréal. All participants signed an informed consent form.

Eight visually impaired persons were recruited through the Institut Nazareth et Louis-Braille (INLB), a rehabilitation agency specializing in vision impairment in the Greater Montreal area, Quebec, Canada. Participants were selected according to the following inclusion criteria: participants must have experienced home modifications for less than 5 years, present adventitious vision impairment (e.g., age-related macular degeneration, glaucoma, diabetic retinopathy), have a visual acuity below 6/21 after correction in both eyes or a visual field below $60^{\circ}$ in the horizontal or vertical meridians, be at least 18 years old, and speak French. Persons who presented a major permanent impairment other than visual (e.g., motor) were excluded. We were unable to meet one participant (emotional disturbance); thus, a total of seven allowed data saturation (Table 1).

Eight ICs were also recruited through the INLB, according to these inclusion criteria: the caregiver had to share a visually impaired person's home or had to have provided significant help for 1 year or more, help or supervise this person in daily living tasks, be at least 18 years old, and speak French. Six participants completed the study (one refused and another was excluded because of the saturation criterion) (Table 1). The caregivers interviewed were not necessarily those of the VIs; in fact, only one dyad was recruited. The diagnosis and severity of the impairment [88-89] of the VIs were taken from their medical records; those of the VIs not interviewed came from the information given by the caregiver.

Participants (visually impaired and caregivers) were met at home for a semistructured individual interview lasting between $11 / 4$ and $3 \mathrm{hr}[87,90]$.

Fifteen professionals, recruited through a nonprobabilistic sampling technique in seven vision rehabilitation agencies in the province of Quebec (Montreal/Longueuil, Quebec City, Repentigny, Trois-Rivières, Sherbrooke, Rouyn, Mont-Joli), met the following criteria: they had to be a professional (rehabilitation teacher [RT], occupational therapist [OT], or orientation and mobility specialist $[\mathrm{O} \& \mathrm{M}]$ ) with a minimum of 5 years of experience with visually impaired adults; be knowledgeable about the home difficulties experienced by the visually impaired population; and speak French. Two refused (death of relative; lack of time) and two did not participate (saturation), so 11 professionals participated in the study (mean = 19.5 years of experience; 6 O\&M, 4 RT, 3 OT), two of whom had two professional degrees (OT, O\&M).

Four mini FGs [83], each composed of three persons, took place for $21 / 4$ to $31 / 2 \mathrm{hr}$. Prior to the meeting, professionals had to read two documents as a basis for the upcoming discussion: the Model of Competence and the user guide for the HOPE $[67,74]$. Both documents were mailed 2 weeks before the meeting, except for two participants who received them 1 week before.

To lead the discussion toward three distinct "questioning routes" [84], depending on the expert groups (one questioning route for the focus group with professionals, another one for the VIs, and a third one for the caregivers), two moderators from outside the study were recruited, along with two assistants who were both assistant 
Table 1.

Description of participants.

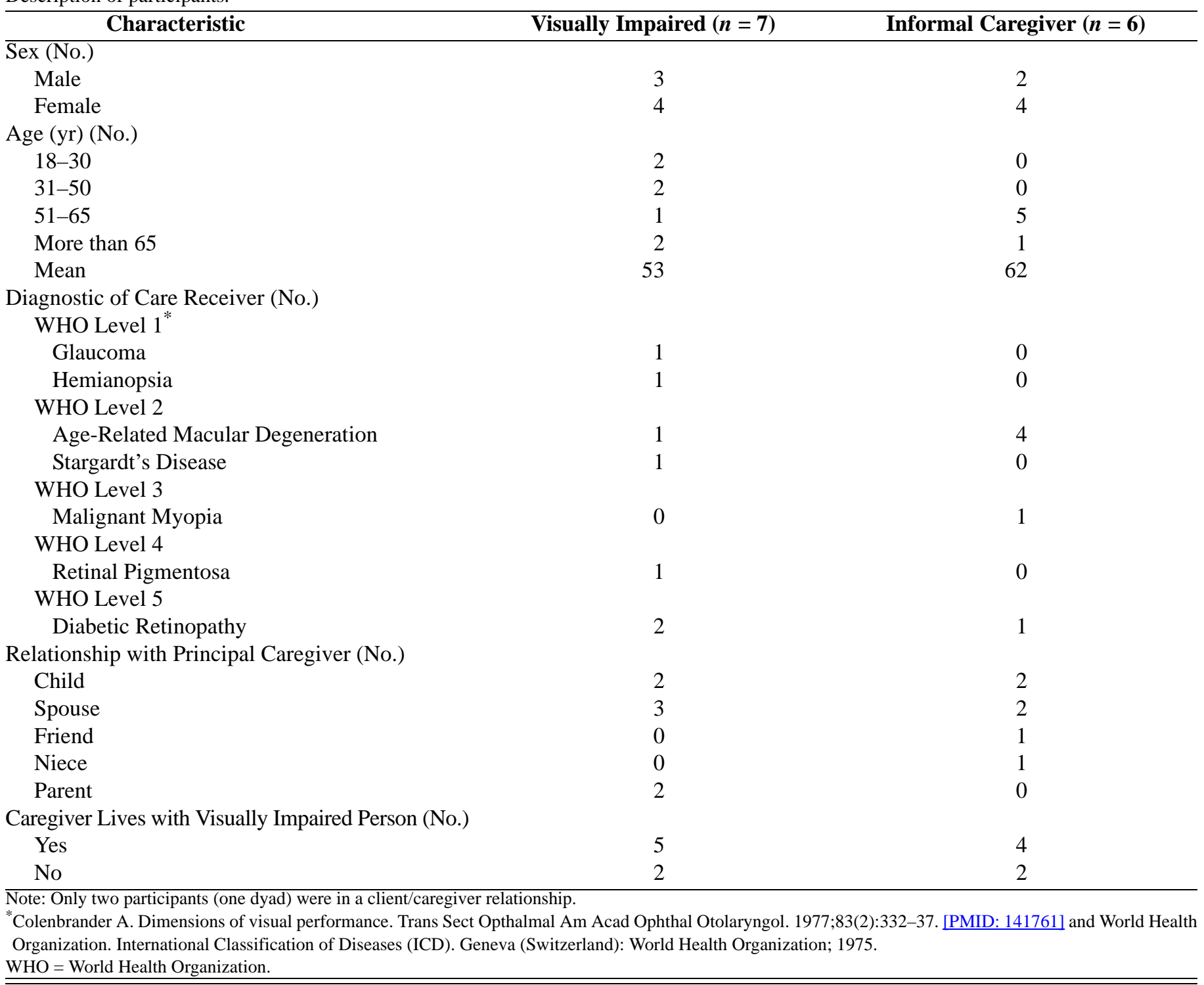

moderators (in FGs) and interviewers (in individual interviews). The moderators had the following characteristics: the first was a psychologist and neuropsychologist with 18 years of experience with interview techniques, such as FGs; the second was an OT student who was trained especially to facilitate these groups. The assistant moderators and interviewers were the first author (MC), who holds an OT(C) and was a master's student in research, and an OT student with a master's degree in administration. Both were trained in interview techniques.

The interview discussions were audiotaped. A content analysis [91] of the data was performed in three phases: integral transcription of data, coding, and computerized-assisted analysis. The integral transcription was performed by an experienced secretary and then checked for content validity by the assistant moderator or the interviewer involved in the data collection. A list of 166 codes and their definitions was constructed based on the concepts of the Model of Competence, the HOPE, and key elements of the interviews. This list was validated with all the researchers. The two interviewers performed coding validation independently on some of the data to ensure agreement between researchers and coders, using QSR N'VIVO 2.0 software (QSR International Pty 
Ltd; Doncaster, Victoria, Australia). Content analysis was performed with an iterative process of explicit and rigorous reductions in distinct outputs of tables inspired by Huberman et al. [92].

\section{RESULTS}

The study showed that some elements of the HOPE do represent the limits faced at home by visually impaired adults. The professionals interviewed agreed that a need exists for a home-based assessment tool that can identify clients' needs and that would have good psychometric properties.

"We realized in our [team] discussions that our ways of searching for information when we are doing our assessment are very different from one another, depending on our past experiences [...] We realized [...] that it doesn't give an equal chance [to clients]" (FG2, lines 96-98).

In general, the professionals agreed with the philosophy of the HOPE, which is administered at home and does not substitute for professional judgment in further intervention choices. They suggested that the HOPE be adapted, highlighting the context of vision rehabilitation, in which short, adaptable, interdisciplinary assessments are needed to serve clients adequately. Specifically, results will be presented regarding (1) terminology, (2) assessment mode, and (3) item relevance. The first two facets were explored with the professionals only and the third with all three expert groups (visually impaired persons, caregivers, and professionals).

\section{Terminology}

The majority of professionals use the "Disability Creation Process" (DCP) classification [93]. Some would like to have an assessment based on this terminology; others emphasize the congruence of the Model of Competence with their day-to-day practice. None distinguish any differences between these two models. "For me, [the Model of Competence] is words that correctly describe what I do. The person, the environment, and interaction between both [...]; it is a model I agree with 100 percent" (FG1, lines 1,929-1,931).

\section{Assessment Mode}

The actual assessment mode used by almost all professionals is an informal interview with the client at home. The interview is based on the client's expressed needs. The environment is evaluated through observations based on professional experience, without any uniformity among professionals. A trial-and-error type assessment is also used (e.g., for lighting). For several professionals, the assessment is not dissociated from the intervention; others, however, stress the importance of evaluation before an intervention: "Solutions, we have plenty of them ... There is often a solution for each situation. It is to evaluate the needs" (FG1, line 1416). Observing the person in activity is also used: "Often, if I just ask, he will say that everything is OK. So putting him in the situation and observing it, I think that says a lot" (FG3, line 189).

Professionals do not use validated assessment tools, explaining that none of them fit with their work "on the ground." Most of them go to the client's home without any assessment tool; some use a homemade assessment tool, such as a list of life habits based on the classification of DCP. The few tools mentioned are technical references based on accessibility norms for public environments [94-95].

The competence scale received mixed reviews on its rating ability. Some participants disagree, finding it too precise, or disagree completely with the principle of using a rating, preferring descriptions to quantification to save time. Others prefer a dichotomous rating, such as "able/not able," a checklist, or a rating to assess intervention results (did or did not reach the goal). Another professional criticized her own lack of analysis in her evaluation: "We have a life habits list. And yes, it is affected, yes, there is something to do, and a goal, but we don't describe the role of the environment in the problem. We don't evaluate!” (FG4, line 514). Finally, some professionals think the rating system is appropriate and clear.

\section{Item Relevance}

Item relevance is presented regarding each concept of the Model of Competence. Concepts are described according to their components (e.g., vanity) and the characteristics of each component (e.g., projecting), according to the comments of all three expert groups (VIs, ICs, and professionals). These characteristics are presented in Table 2.

\section{Concept: Nonhuman Environment}

Except for the component "electrical and household appliances," which professionals would like to be more detailed (e.g., cooking appliance, toaster), the components of the HOPE are appropriate. However, the home characteristics to be assessed in a vision rehabilitation 
CARIGNAN et al. New assessment tool of person-environment interaction for visually impaired

Table 2.

Relevant characteristics for assessment in vision rehabilitation, grouped by concepts of Model of Competence.

\begin{tabular}{|c|c|}
\hline Concept & Characteristics \\
\hline Nonhuman Environment & $\begin{array}{l}\text { Lighting (quantity, position/direction, glare) } \\
\text { Color and contrast } \\
\text { Presence of landmarks (visual, tactile, auditory, kinesthetic) } \\
\text { Organization and familiarity (e.g., arrangement of objects/furniture, projecting objects, unevenness, } \\
\text { simplicity of perception) } \\
\text { Size of elements } \\
\text { Potential for change (moving, light changes with day/night or seasons) }\end{array}$ \\
\hline Human Environment & $\begin{array}{l}\text { Recent changes (e.g., widow) } \\
\text { Interpersonal quality (person and caregiver) } \\
\text { Living together or not } \\
\text { Understanding pathology and person's experiences } \\
\text { Caregiver capacities } \\
\text { Expectations and concerns } \\
\text { Psychological reaction to disability } \\
\text { Compliance/resistance to interventions } \\
\text { Satisfaction with interventions }\end{array}$ \\
\hline Person & $\begin{array}{l}\text { Vision functions (acuity, vision field, sensitivity to light and contrast) } \\
\text { Perceptual skills (visual, auditory, tactile, proprioceptive) } \\
\text { Associated conditions: motor (e.g., pain, sensitivity, coordination, balance), cognitive (e.g., memory), } \\
\text { affective (e.g., depression), and sensory (e.g., auditory, tactile deficit) } \\
\text { Priorities (values and culture) } \\
\text { Perceived level of competence } \\
\text { Adaptation to vision loss (psychological) } \\
\text { Receptivity to changes } \\
\text { Injury (e.g., burns, bruises) } \\
\text { Potential for change (disease progression, learning new techniques, change in perception) }\end{array}$ \\
\hline Role & $\begin{array}{l}\text { Desire for role recovery } \\
\text { Expectation of person, not those of society (culture) } \\
\text { Compensation by informal caregiver } \\
\text { Compensation by paid caregivers } \\
\text { Roles and responsibilities not compensated (congruence between caregiver's capacities and } \\
\quad \text { person's needs) }\end{array}$ \\
\hline
\end{tabular}

context are different from those in the HOPE (Table 2); for example, "light, contrast, and organization" replace "material and type of handle." The stability of these elements over time is also a concern (e.g., light changes between day and night).
Apart from the components related to home, participants mentioned other environments that might be evaluated: school, work, restaurant, bank, friends' homes, outdoors, mall, supermarket, convenience store, drugstore, and community recreational center. 


\section{Concept: Human Environment}

The importance of assessing the human environment is a subject for disagreement among participants. Some professionals consider assessing the human environment unrealistic because of administrative constraints and waiting lists. Others consider its systematic assessment crucial: "for the elderly, this link [person-caregiver] is so crucial, it is part of the solution. So, if we don't look at this, we ignore an element of the solution” (FG3, line 614). A VI mentioned the importance of assessing caregivers:

\section{"Never forget the spouse in your evaluation [...], the spouse also has progress to make. She does it through the disabled person, of course, but she has some things to do for herself. [...] You know, her eyes and mine, sometimes, it is not the same thing." (VI4, lines 801-844)}

Professionals make sure of the potential presence of a caregiver (spouse, children, relatives, friends, and neighbors) during the evaluation period. The feeling of security among strangers was also mentioned. For professionals, the ideal assessment, without time limits, would systematically document the characteristics listed in Table 2.

\section{Concept: Person}

Professionals agree with the principle of the HOPE's preliminary tests. But, because they are physical tests (e.g., pain, sensitivity, coordination, balance), some of them are inappropriate and must be considered as indicating comorbidity with visual deficits; therefore, the current tests are not sufficient. The professionals would prefer to document visual function (Table 2) as preliminary tests.

At home, professionals assess clients' perception of their competence level to prioritize the intervention activities. "A woman said, 'Your little gadget [water level indicator], I don't want it. I put my coffee cup on two Scott towels, I pour the water and stir it up. If it overflows, I don’t care!'” (FG4, line 484).

Other characteristics mentioned (Table 2) are injuries, incident cues, and psychological elements (e.g., adaptation to vision loss, receptivity to changes). As these participants said: "I think I need more help. But you know, I'm not there yet" (VI1, line 82). "You know, the white cane is the universal symbol of blindness" (VI4, line 333). Some people also talked about the influence of the cultural aspects of adaptation to vision loss; one participant was an immigrant.

\section{Interaction Concept: Activity}

In current practice, activities likely to be affected by different levels of severity of visual impairment appear on some assessment checklists. Some components of these activities are different from those in the HOPE. For example, one potential difficulty is not simply accessing a closet, but locating something inside it. This vision checklist may have such elements as read (letter/number), note/write, locate/choose, detect/pinpoint, identify, travel/move, orient oneself, control, monitor, and clean/ maintain. Reported characteristics of such activities are presented in Table 2; for example, the strategies used to carry out an activity are mentioned.

\section{Interaction Concept: Role}

Visual impairment affects a person's responsibilities which, in turn, affects interpersonal relationships. At home, the roles of spouse, parent, and grandparent are particularly affected.

"I have a six-year-old granddaughter, [I am] preparing a meal and she tries to help ...W We have encouraged her to do so [...] But now [...] I can't do things where it might be unsafe for her [like cutting veggies], I limit our activities. [...] It turns our whole family life upside down” (VI6 lines 393-402; 453).

In the sample, a heavy burden on caregivers was observed.

"The message that I would give [to another caregiver like me]? If you want to do it, set your limits ... Me, I didn't set my limits... That was my problem. And when it's not fine, say so. Say it! I didn't do that. I kept all this inside of me. You can get sick when you don't set limits.” (IC5, line 282).

A distinction was made between younger and older adults' expected roles, including the cultural aspects of this distinction. Role components were more often mentioned by visually impaired participants and caregivers than by professionals. The professionals agreed with the importance of assessing roles, even if they do not currently do so. "I would keep the beauty of the assessment in the role part" (FG3, line 614). Relevant characteristics to be assessed in vision rehabilitation are described in Table 2. 


\section{DISCUSSION}

Based on these results, we developed the French language version of the HOPE for Visually Impaired Adults (HOPE-Visual Version) (Appendix 1, available online only at http://www.rehab.research.va.gov/jour/08/45/7/pdf/ contents.pdf) [51,96-97]. This assessment tool, which is separate from the HOPE, is specific to visually impaired clients 18 years and older. As part of a battery of tests analyzing the person-environment interaction at home [98], the HOPE-Visual Version could eventually be used as a complementary tool for clients with motor, cognitive, and visual disabilities.

\section{Terminology and Assessment Mode}

The Model of Competence offers a comprehensive, systematic, and in-depth understanding of the interaction between the person and his or her home environment. As mentioned in the literature review, existing assessment tools with observational and interview modes are not based on a conceptual framework of the person-environment relationship. These assessment tools fail to consider the many dimensions of the environment and the person from a client-centered point of view [35-43]. Because each client and each home are unique, professionals need an assessment tool based on a conceptual framework [17,21-22,62-63]. The Model of Competence [66] was kept as the framework for the HOPE-Visual Version [51,96-97]. This model should be better explained to professionals who will use the assessment tool.

The present study, as well as the literature, reveal the importance of centering the assessment on the client's expressed needs [62]. As mentioned earlier, this source of information alone cannot guarantee the person's competence level or the handicap-created situation; observing the situation in action allows the professional to verify the person's interaction with the environment $[15,25,51]$. Thus, assessment tools that combine both assessment modes are valuable. In accordance with the literature $[7-8,12,67]$ and this study, the HOPE-Visual Version includes assessment modes such as observation and clientcentered individual interviews. Since professionals are familiar with informal interviews, the semistructured interview in the HOPE-Visual Version offers them flexibility. It covers more than the predefined items of existing instruments that use a questionnaire [35-37,3940,42-43]. The client can also pinpoint activities and roles that are significant.

\section{Environment}

Although the HOPE focuses on the home environment, participants commented on other environments. The Model of Competence's [26,76] conceptualization of the environment, based on Bronfenbrenner's definitions (microsystem, mesosystem, exosystem, macrosystem) $[27,74]$, allows for expansion to other environments. Briefly, the microsystem is the person's immediate environment (e.g., home, school, work). The mesosystem refers to the relationship between the microsystems in which the person operates. The exosystem includes the relationship between microsystems not including the person, but in which internal events influence the person. Finally, the macrosystem refers to the cultural environment. Professionals are interested in other microsystems (work, restaurant), but their analysis remains at the microsystemic level because the HOPE tool does not pinpoint the relationship between these microsystems. With this systemic view of the environment, the HOPE-Visual Version [51,96-97] can focus on the difficulties experienced by visually impaired adults and the specificities of each environment used. For example, the difficulties experienced at home can be very different from those in a restaurant. The HOPE-Visual Version will reveal these differences.

\section{Administrative Constraints}

Some administrative constraints concern professionals, mostly the reduced time for assessment; in their view, an assessment without a rating scale would be faster. In remote areas, professionals who must cover a large territory wish to optimize their travel time by doing some interdisciplinary evaluations. These time constraints, which have also been noted in the literature [62], were considered in the development of the HOPE-Visual Version, but all the scales of the original HOPE were kept (Appendix 1). These scales are essential for establishing psychometric properties, which are lacking in several existing assessment tools [28,30,39-40].

\section{Dissociation Between Assessment and Intervention}

The disparity in opinions of the competence scale is an indicator of the diversity of professionals' assessment. Several do not see how a formal assessment can be useful, preferring to intervene as they observe problems. This confusion between evaluation and intervention becomes clear when professionals talk about evaluation-they may mention technical references for intervention rather 
than assessment tools. The distinction may be debatable but it conforms to the vision rehabilitation literature [8]. From our point of view, the distinction between assessment and intervention is important because it avoids a bias in collecting information and allows the professional to obtain a global perspective before the intervention.

\section{Item Relevance}

\section{Nonhuman Environment and Person}

The person and environment characteristics mentioned in Table 2 concur with the vision rehabilitation literature [8,12,99-103]. Nonhuman environment characteristics, such as color, contrast, lighting, and organization, are well documented in the literature, but they were not previously addressed in an assessment tool with a measurement scale and published psychometric studies.

Adaptation to vision loss is an element that should be included in an assessment of the person-environment relationship at home because it influences interventions [104]. As our results show, some clients are not ready to accept help; the adaptation to vision loss is an ongoing process and its level will facilitate or slow down the intervention. This aspect is measured with some assessment tools [104-106], but not from a person-environment perspective as it is suggested in the HOPE-Visual Version [51,96-97]. If the problem is major, these assessment tools could be combined.

Another aspect that is not well covered in this study is the significance of home. The meaning of "home" includes such aspects as familiarity and routines developed over time and the symbolic aspects of cherished places and objects, as evaluated by Oswald et al. [19]. Documenting this aspect would be beneficial because professionals may be able to relate it to some difficult situations experienced by the clients during interventions. Although not specific to this concept, the section of the HOPE-Visual Version concerning the adaptation to vision loss captures part of it.

\section{Human Environment}

In the vision rehabilitation literature concerning younger and older adults, the human environment is often considered separately during an evaluation. An analysis feature of the original HOPE was to include in the home-based assessment process the partners' reciprocal expectations and capacities [20,22,67,74]. The role assessment of the HOPE-Visual Version contains this same feature.
Horowitz et al. underscore the importance of evaluating the congruence between the visually impaired person's and the caregiver's perceptions [14]. Convergence between these two perceptions and that of the evaluators ensures that reliable conclusions will be drawn [15]. The reaction to vision loss, the family's understanding of the person's visual condition, and the congruence between their perceptions of the situation are themes present in the literature [14] but are not targeted by assessment tools. The HOPE-Visual Version provides an innovative solution to this problem by including these aspects [51,96-97].

\section{Activity}

To carry out actions, one makes different demands on his or her motor and visual systems. But the hierarchical structure of activity [107] - that is, activity, task, and operation-can be retained from the motor version [20,22,68] (Appendix 2, available online only at http:// www.rehab.research.va.gov/jour/08/45/7/pdf/contents.pdf). The originality of this design is that the activity is considered the content of the interaction between the person and his or her environment [22]. In the Model of Competence [65] and in the HOPE [20,67], the activity represents the interaction between the person and the environment- that is, the relationship between the person and his or her nonhuman environment is mainly observed in activities [66].

\section{Role}

Also relevant is the assessment of roles, such as the content of an interaction between the person and the environment, because of the emerging literature related to this subject in vision impairment [14]. Although role is not assessed by professionals, at least not in any depth, the professional group recognized the relevance of this kind of assessment. In the HOPE-Visual Version, role components and characteristics are similar to those in the HOPE; the home-based assessment of role is an innovative approach. No assessment tool validated for adults with visual impairments includes an analysis of the concept of role [51].

\section{Study Strengths}

The strengths of this study lie in the triangulation of the three groups of experts [87], the diversity of the rehabilitation centers consulted, and the experienced professionals recruited. The mini-FG technique facilitates in-depth discussions, because of the low number of participants [84]. Interviews with visually impaired adults and caregivers 
CARIGNAN et al. New assessment tool of person-environment interaction for visually impaired

at home, with ecological validity, minimize the risk of recall problems and collect more details on interventions that have (or have not) taken place in the home.

\section{Study Limitations}

The interviewers' lack of experience is a limitation. One hour of FG tape was lost (broken tape), but this content was rewritten with the moderator assistant's notes. The caregiver sample contained a high proportion of caregivers of elderly people. This limits the study's transferability, but this sample may adequately represent the population of caregivers of visually impaired persons; a similar sample with similar criteria was obtained in Silva-Smith et al.'s study [108].

\section{CONCLUSIONS}

This study validated the content of the HOPE-Visual Version [51,96-97]. A reliability study of this assessment tool will be conducted in the near future. With an analysis structure based on a person-environment theoretical model, this new assessment tool fills a scientific and clinical gap, optimizes the evaluation process, and informs interventions by providing an understanding of the home context. This assessment tool is part of a battery of tests assessing the person-environment interaction at home for child, adult, and elderly populations affected by motor, cognitive, or visual disabilities, from a person-environment relationship perspective.

\section{ACKNOWLEDGMENTS}

We warmly thank all the participants for their generosity and their comments.

This material was based on work supported in part by the Fonds de la recherche en santé du Québec, grant 3825-12. Scholarships were offered to Mathieu Carignan by the Quebec Rehabilitation Research Network and the Fonds de la recherche en santé du Québec, grant 5481.

The authors have declared that no competing interests exist.

\section{REFERENCES}

1. Gresset J. Visual impairment and blindness in Canada: actual and future demography [Déficience visuelle et cécité au Canada—Démographie présente et future]. In: Proceedings of the Symposiums scientifiques sur l'incapacité visuelle et la réadaptation; 2004 Mar 10; Montréal (Canada).

2. Gresset J, Baumgarten M. Prevalence of visual impairment and utilization of rehabilitation services in the visually impaired elderly population of Quebec. Optom Vis Sci. 2002;79(7):416-23. [PMID: 12137395$]$

3. Massof RW. A model of the prevalence and incidence of low vision and blindness among adults in the U.S. Optom Vis Sci. 2002;79(1):31-38. [PMID: 11828896]

4. Crews JE, Campbell VA. Health conditions, activity limitations, and participation restrictions among older people with visual impairments. J Vis Impair Blind. 2001;95(8): 453-67.

5. Faye EE. Functional consequences of vision impairment: Visual function related to eye pathology. In: Silverstone $B$, editor. The Lighthouse handbook on vision impairment and vision rehabilitation. Oxford (England): Oxford University Press; 2000. p. 791-98.

6. Horowitz A. Vision impairment and functional disability among nursing home residents. Gerontologist. 1994;34(3): 316-23. [PMID: 8076872]

7. Ellexson MT. Access to participation: Occupational therapy and low vision. Top Geriatr Rehabil. 2004;20(3):154-72.

8. Lueck AH. Functional vision: A practitioner's guide to evaluation and intervention. New York (NY): American Foundation for the Blind; 2004.

9. Markowitz M. Occupational therapy interventions in low vision rehabilitation. Can J Ophthalmol. 2006;41(3):340-47. [PMID: 16767190]

10. Massof RW, Alibhai SS, Deremeik JT, Glasner NM, Baker FH, DeRose JL. Low vision rehabilitation: Documentation of patient evaluation and management. J Vis Rehabil. 1996;10(2):3-31.

11. Scheiman M, Scheiman M, Whittaker SG. Overview of treatment strategy: Model of care for low vision rehabilitation. In: Scheiman M, Scheiman M, Whittaker SG, editors. Low vision rehabilitation: A practical guide for occupational therapists. Thorofare (NJ): Slack Inc.; 2007. Available from: http://www.slackbooks.com/excerpts/37344/ 37344.asp

12. Watson GR. Functional assessment of low vision for activities of daily living. In: Silverstone B, editor. The Lighthouse handbook on vision impairment and vision rehabilitation. Oxford (England): Oxford University Press; 2000. p. 869-84.

13. Wolffe KE. Adults with low vision: Personal, social, and independent living needs. In: Corn AL, Koenig AJ, editors. Foundations of low vision: Clinical and functional perspectives. New York (NY): AFB Press; 1996. p. 322-39. 
14. Horowitz A, Goodman CR, Reinhardt JP. Congruence between disabled elders and their primary caregivers. Gerontologist. 2004;44(4):532-42. [PMID: 15331810]

15. Diehl M. Everyday competence in later life: Current status and future directions. Gerontologist. 1998;38(4):422-33. [PMID: 9726129]

16. Gitlin LN. Conducting research on home environments: Lessons learned and new directions. Gerontologist. 2003; 43(5):628-37. [PMID: 14570959]

17. Iwarsson S, Stahl A. Accessibility, usability and universal design-Positioning and definition of concepts describing person-environment relationships. Disabil Rehabil. 2003; 25(2):57-66. [PMID: 12554380$]$

18. Letts L, Law M, Rigby P, Cooper B, Stewart D, Strong S. Person-environment assessments in occupational therapy. Am J Occup Ther. 1994;48(7):608-18. [PMID: 7943150]

19. Oswald F, Schilling O, Wahl HW, Fange A, Sixsmith J, Iwarsson S. Homeward bound: Introducing a four-domain model of perceived housing in very old age. J Environ Psychol. 2006;26(3):187-201.

20. Rousseau J. Assessment tool development of the measure of handicap-created situations in home-dwelling environment for adults facing motor impairments. [Élaboration d'un instrument de mesure de la situation de handicap en milieu de vie naturel pour l'adulte présentant des incapacités motrices] [thesis]. Montréal (Canada): Université de Montréal; 1997.

21. Rousseau J, Potvin L, Dutil E, Falta P. Understanding the issue of home adaptation: Searching for a conceptual framework. Occup Ther Health Care. 2002;14(1):27-38.

22. Rousseau J, Potvin L, Dutil E, Falta P. A critical review of assessment tools related to home adaptation issues. Occup Ther Health Care. 2002;14(3/4):93-104.

23. Stevens-Ratchford R, Krause A. Visually impaired older adults and home-based leisure activities: The effects of person-environment congruence. J Vis Impair Blind. 2004; 98(1):14-27.

24. Wahl HW, Oswald F, Zimprich D. Everyday competence in visually impaired older adults: A case for personenvironment perspectives. Gerontologist. 1999;39(2): 140-49. [PMID: 10224710]

25. Wahl HW, Oswald F. The person-environment perspective of vision impairment. In: Silverstone B, editor. The Lighthouse handbook on vision impairment and vision rehabilitation. Oxford (England): Oxford University Press; 2000. p. 1069-88.

26. Bronfenbrenner U. The ecology of human development: Experiments by nature and design. Cambridge (MA): Harvard University Press; 1979.

27. Rousseau J. The Model of Competence-the Home Assessment of Person-Environment Interaction (HOPE). [Le Modèle de Compétence-_l'Évaluation à domicile de l'interaction personne-environnement (ÉDIPE)]. Québec (Canada): Limited distribution document (available by contacting the author at the Département de réadaptation (ergothérapie), Centre d'hébergement Ferdinand-Vandry, Université Laval, Sainte-Foy, Québec, Canada, G1K 7P4); 1999.

28. Altangerel U, Spaeth GL, Steinmann WC. Assessment of function related to vision (AFREV). Ophthalmic Epidemiol. 2006;13(1):67-80. [PMID: 16510349]

29. Babcock-Parziale JL, McKnight PE, Head DN. Evaluating psychometric properties of a clinical and a self-report blind rehabilitation outcome measure. J Rehabil Res Dev. 2005;42(4):487-98. [PMID: 16320144$]$

30. Dahlin-Ivanoff S, Sonn U, Svensson E. Development of an ADL instrument targeting elderly persons with agerelated macular degeneration. Disabil Rehabil. 2001;23(2): 69-79. [PMID: 11214718]

31. De l'Aune W, Williams M, Welsh RL. Outcome assessment of the rehabilitation of the visually impaired. J Rehabil Res Dev. 1999;36(4):273-93. [PMID: 10678451]

32. De l'Aune WR, Williams MD, Watson GR, Schuckers P, Ventimiglia G. Clinical application of a self-report, functional independence outcomes measure in the DVA's Blind Rehabilitation Service. J Vis Impair Blind. 2004;98(4): 197-211.

33. Hart PM, Chakravarthy U, Stevenson MR, Jamison JQ. A vision specific functional index for use in patients with age related macular degeneration. Br J Ophthalmol. 1999; 83(10):1115-20. [PMID: 10502569]

34. Hart PM, Stevenson MR, Montgomery AM, Muldrew KA, Chakravarthy U. Further validation of the Daily Living Tasks Dependent on Vision: Identification of domains. Br J Ophthalmol. 2005;89(9):1127-30. [PMID: 16113365]

35. Haymes SA, Johnston AW, Heyes AD. A weighted version of the Melbourne Low-Vision ADL Index: A measure of disability impact. Optom Vis Sci. 2001;78(8):565-79. [PMID: 11525547]

36. Haymes SA, Johnston AW, Heyes AD. Preliminary investigation of the responsiveness of the Melbourne Low Vision ADL Index to low-vision rehabilitation. Optom Vis Sci. 2001;78(6):373-80. [PMID: 11444625$]$

37. Haymes SA, Johnston AW, Heyes AD. The development of the Melbourne Low-Vision ADL Index: A measure of vision disability. Invest Ophthalmol Vis Sci. 2001;42(6): 1215-25. [PMID: 11328730]

38. Head DN, Babcock JL, Goodrich GL, Boyless JA. A geriatric assessment of functional status in vision rehabilitation. J Vis Impair Blind. 2000;94(6):357-71.

39. Long RG. Functional Independence Measure for Blind Adults (FIMBA). Atlanta (GA): Department of Veterans Affairs Rehabilitation Research \& Development; 1993. 
40. Long RG, Crews JE, Mancil R. Creating measures of rehabilitation outcomes for people who are visually impaired: The FIMBA project. J Vis Impair Blind. 2000; 94(5):292-306.

41. Nutheti R, Shamanna BR, Krishnaiah S, Gothwal VK, Thomas R, Rao GN. Perceived visual ability for functional vision performance among persons with low vision in the Indian state of Andhra Pradesh. Invest Ophthalmol Vis Sci. 2004;45(10):3458-65. [PMID: 15452050]

42. Pankow L, Luchins D, Studebaker J, Chettleburgh D. Evaluation of a vision rehabilitation program for older adults with visual impairment. Top Geriatr Rehabil. 2004;20(3):223-32.

43. Ross CK, Stelmack JA, Stelmack TR, Guihan M, Fraim M. Development and sensitivity to visual impairment of the Low Vision Functional Status Evaluation (LVFSE). Optom Vis Sci. 1999;76(4):212-20. [PMID: 10333183]

44. Schmier JK, Halpern MT, Covert D. Validation of the Daily Living Tasks Dependent on Vision (DLTV) questionnaire in a U.S. population with age-related macular degeneration. Ophthalmic Epidemiol. 2006;13(2):137-43. [PMID: 16581618]

45. Sellers SW, Fisher AG, Duran LJ. Validity of the assessment of motor and process skills with students who are visually impaired. J Vis Impair Blind. 2001;95(3):164-66.

46. Stelmack JA, Szlyk JP, Stelmack BR, Demers-Turco P, Williams RT, Moran D, Massof RW. Psychometric properties of the Veterans Affairs Low-Vision Visual Functioning Questionnaire. Invest Ophthalmol Vis Sci. 2004; 45(11):3919-28. [PMID: 15505037]

47. Szlyk JP, Arditi A, Bucci PC, Laderman D. Self-report in functional assessment of low vision. J Vis Impair Blind. 1990;84(2):61-66.

48. Weih LM, Hassell JB, Keeffe J. Assessment of the impact of vision impairment. Invest Ophthalmol Vis Sci. 2002; 43(4):927-35. [PMID: 11923230]

49. Massof RW, Ahmadian L, Grover LL, Deremeik JT, Goldstein JE, Rainey C, Epstein C, Barnett GD. The Activity Inventory: an adaptive visual function questionnaire. Optom Vis Sci. 2007 Aug;84(8):763-74. [PMID:17700339]

50. Babcock-Parziale JL, Williams MD. Historical perspective on the development of outcomes measures for lowvision and blind rehabilitation in the Department of Veterans Affairs. J Rehabil Res Dev. 2006;43(6):793-808. [PMID: 17310428$]$

51. Carignan M. Development of an assessment tool of the person-environment relationship for home-dwelling visually impaired population. [Élaboration d'un instrument d'évaluation de la relation personne-environnement pour la clientèle ayant des incapacités visuelles vivant à domicile] [thesis]. Montréal (Canada): Université de Montréal; 2007.
52. De Boer MR, Moll AC, De Vet HC, Terwee CB, VolkerDieben HJ, Van Rens G. Psychometric properties of vision-related quality of life questionnaires: A systematic review. Ophthalmic Physiol Opt. 2004;24(4):257-73. [PMID: 15228503$]$

53. Massof RW, Rubin GS. Visual function assessment questionnaires. Survey Ophthalmal. 2001;45(6):531-48. [PMID: 11425359]

54. Margolis MK, Coyne K, Kennedy-Martin T, Baker T, Schein O, Revicki DA. Vision-specific instruments for the assessment of health-related quality of life and visual functioning: A literature review. Pharmacoeconomics. 2002;20(12):791-812. [PMID: 12236802]

55. Mitchell J, Bradley C. Quality of life in age-related macular degeneration: A review of the literature. Health Qual Life Outcomes. 2006;4:97. [PMID: 17184527]

56. Stelmack J. Quality of life of low-vision patients and outcomes of low-vision rehabilitation. Optom Vis Sci. 2001; 78(5):335-42. [PMID: 11384011]

57. Slay DH. Home-based environmental lighting assessments for people who are visually impaired: Developing techniques and tools. J Vis Impair Blind. 2002;96(2):109-14.

58. Mann WC, Hurren D, Karuza J, Bentley DW. Needs of home-based older visually impaired persons for assistive devices. J Vis Impair Blind. 1993;87(4):106-10.

59. Petty LS, McArthur L, Treviranus J. Clinical report: Use of the Canadian Occupational Performance Measure in vision technology. Can J Occup Ther. 2005;72(5):309-12. [PMID: 16435592]

60. Whiteneck GG, Harrison-Felix CL, Mellick DC, Brooks CA, Charlifue SB, Gerhart KA. Quantifying environmental factors: A measure of physical, attitudinal, service, productivity, and policy barriers. Arch Phys Med Rehabil. 2004;85(8):1324-35. [PMID: 15295760]

61. Crews JE, Long RG. Conceptual and methodological issues in rehabilitation outcomes for adults who are visually impaired. J Vis Impair Blind. 1997;91(2):117-30.

62. La Grow SJ. Measuring rehabilitation outcomes for visually impaired persons in New Zealand. J Vis Impair Blind. 2000;94(5):322-27.

63. Keith RA. Conceptual basis of outcome measures. Am J Phys Med Rehabil. 1995;74(1):73-80. [PMID: 7873118$]$

64. Reed KL. Theory and frame of reference. In: Willard HS, Spackman CS, Neistadt ME, Crepeau EB, editors. Willard and Spackman's occupational therapy. 9th ed. Philadelphia (PA): Lippincott-Raven Publishers; 1998. p. 521-23.

65. Nunnally JC. Psychometric theory. 2nd ed. New York (NY): McGraw-Hill; 1978.

66. Rousseau J, Potvin L, Dutil E, Falta P. Model of competence: A conceptual framework for understanding the personenvironment interaction for persons with motor disabilities. Occup Ther Health Care. 2002;16(1):15-36. 
67. Rousseau J. Home Assessment of Person-Environment Interaction (HOPE) [L'Évaluation à domicile de l'interaction personne-environnement (ÉDIPE)], version 2.2 Québec. Limited distribution training document (available by contacting the author at the Centre de recherche, Institut universitaire de gériatrie de Montréal, 4565, Queen-Mary, Montréal, Québec, Canada, H3W 1W5); 2003.

68. Rousseau J, Villeneuve S, Allard H, Bourget A, Bélanger $\mathrm{D}$, Toupin K, editors. Test-retest reliability study of home assessment of person-environment interaction. In: Proceedings of the 7th European Congress of Occupational Therapy-Building the Future; 2004 Sep; Athens (Greece).

69. Bourget A. Inter-rater reliability study of the Home Assessment of Person-Environment Interaction (HOPE) [Étude de fidélité interexaminateurs de L'Évaluation à domicile de l'interaction personne-environnement (ÉDIPE)] [thesis]. Québec (Canada): Université Laval; 2002.

70. Allard H. Development and content validation of the pediatric version of the Home Assessment of PersonEnvironment Interaction [Développement et validation de contenu de la version pédiatrique de l'Évaluation à domicile de l'interaction personne-environnement (ÉDIPE)] [thesis]. Montréal (Canada): Université de Montréal; 2006.

71. Allard H, Rousseau J, Feldman D, Majnemer A. A new assessment tool in home modification for pediatrics. [Nouvel instrument d'évaluation en aménagement domiciliaire pour la pédiatrie]. In: Proceedings of the Canadian Association of Occupational Therapy Conference-Evidence and Occupation: Building the Future; 2006 Jun; Montréal (Canada). Canadian Journal of Occupational Therapy Conference Program Supplement, 1(73), 1 Abstract S45. p. 57.

72. Rousseau J, Ska B, St-Arnaud A. HOPE-cognitive version [ÉDIPE-version cognitive]. Montréal. Limited distribution document (available by contacting the author at the Centre de recherche, Institut universitaire de gériatrie de Montréal, 4565, Queen-Mary, Montréal, Quebec, Canada, H3W 1W5); 2005.

73. Anastasi A. Introduction à la psychométrie. Montréal (Canada): Guérin Universitaire; 1997. ISBN: 2760133699 (2-7601-3369-9).

74. Rousseau J. The Model of Competence [Le Modèle de Competence]. Limited distribution training document (available by contacting the author at the Centre de recherche, Institut universitaire de gériatrie de Montréal, 4565, Queen-Mary, Montréal, Québec, Canada, H3W 1W5); 2003.

75. Capra F. The time of change: Science, society and new culture P. [Le temps du changement: science, société et nouvelle culture]. Monaco: Éd. du Rocher; 1983.

76. Bronfenbrenner U. Toward an experimental ecology of human development. Am Psychol. 1977;32(7):515-31.
77. Mosey AC. Psychosocial components of occupational therapy. New York (NY): Raven Press; 1986.

78. Sarbin TR, Allen VL. Role theory. In: Lindzey G, Aronson E, editors. Handbook of social psychology. 2nd ed. Reading (MA): Addison-Wesley Publishing Co.; 1968. p. 488-567.

79. Breines E. An attempt to define purposeful activity. Am J Occup Ther. 1984;38(8):543-44. [PMID: 6476073]

80. Rogers JC. The Spirit of Independence: The evolution of a philosophy. Am J Occup Ther. 1982;36(11):709-15. [PMID: 7158648]

81. White RW. Motivation reconsidered: The concept of competence. Psychol Rev. 1959;66:297-333. [PMID: 13844397]

82. Canadian Society of the ICIDH, Comité québécois sur la CIDIH. Réseau International CIDIH: The disability creation process: analysis of the consultation-new propositions [Le processus de production des handicaps: Analyse de la consultation-Nouvelles propositions]. Québec (Canada): Compo-Alphatek. 1991;4(1-2).

83. Contandriopoulos AP, Champagne F, Potvin L, Denis JL, Boyle P. How to prepare a research: to define it, to structure it and to finance it [Savoir préparer une recherche: La définir, la structurer, la financer]. Montréal (Canada): University of Montréal Press [Presses de l’Université de Montréal]; 1990.

84. Krueger RA. Focus groups: A practical guide for applied research. 2nd ed. Thousand Oaks (CA): Sage Publications; 1994.

85. Gubrium JF, Holstein JA. Handbook of interview research: Context and method. Thousand Oaks (CA): Sage Publications; 2001.

86. Mayer R, Ouellet F. Methodology of research for social workers [Méthodologie de recherche pour les intervenants sociaux]. Boucherville (Canada): Gaëtan Morin; 1991.

87. Denzin NK, Lincoln YS. Handbook of qualitative research. Thousand Oaks (CA): Sage Publications; 1994.

88. Colenbrander A. Dimensions of visual performance. Trans Sect Opthalmal Am Acad Ophthal Otolaryngol. 1977;83(2):332-37. [PMID: 141761]

89. World Health Organization. International Classification of Diseases (ICD). Geneva (Switzerland): World Health Organization; 1975.

90. Moore LW. Conducting research with visually impaired older adults. Qual Health Res. 2002;12(4):559-65.

[PMID: 11939254$]$

91. Van Der Maren JM. Research methods in education [Méthodes de recherche pour l'éducation]. 2nd ed. Montréal (Canada): University of Montréal Press [Presses de l’Université de Montréal]; 1996.

92. Huberman AM, Miles MB. Analysis of qualitative data [Analyse des données qualitatives. Recueil de nouvelles méthodes]. Brussels (Belgium): Editions du Renouveau pedagogique; de boeck université; 1991. 
93. Fougeyrollas P, Noreau L, Bergeron H, Cloutier R, Dion S, St-Michel G. Social consequences of long term impairments and disabilities: Conceptual approach and assessment of handicap. Int J Rehabil Res. 1998;21(2):127-41. [PMID: 9924676]

94. Universal accessibility practical guide [Guide pratique d'accessibilité universelle]. Québec (Canada): Institut de réadaptation en déficience physique de Québec; 2003 [updated 2003; cited April 12, 2006]; Available from: http://www.irdpq.qc.ca/

95. Ratelle A, Lemay L, Kreis S. Accessibility criteria for the needs of visually impaired persons: A practical tool for place modifications [Critères d'accessibilité répondant aux besoins des personnes ayant une déficience visuelle: Un outil pratique pour l'aménagement des lieux.] Longueuil (Canada): Société Logique/Institut Nazareth et LouisBraille; 2003.

96. Carignan M, Rousseau J, Gresset J, Couturier JA. Home assessment of person-environment interaction for homedwelling visually impaired population: The HOPE-Visual Version [Évaluation à domicile de l'interaction personneenvironnement pour la clientèle ayant des incapacités visuelles: ÉDIPE-version visuelle]. Limited distribution document. 2007.

97. Carignan M, Rousseau J, Gresset J, Couturier JA. A new home-based rehabilitation assessment tool for visually impaired persons. In: Proceedings of the 2007 Canadian Association of Occupational Therapy Conference-Leading the Way to Healthy Occupation; 2007 Jul; St. John’s (Newfoundland).

98. Rousseau J, Allard H, Carignan M, Ska B, St-Arnaud A, Gresset J. Analysing person-environment interaction at home: A battery of tests. In: Proceedings of the 2007 Canadian Association of Occupational Therapy Conference-Leading the Way to Healthy Occupation; $2007 \mathrm{Jul}$; St. John's (Newfoundland).

99. Christiaen M-P. Vivre mieux dans un environnement visuel adapté: Lumières, contrastes et repères au service des personnes âgées en EMS. Geneva (Switzerland):
Association pour le Bien des Aveugles et malvoyants; 2004. Available from: http://www.abage.ch/themes/EnvironmentVisuel.aspx/.

100. Institut Nazareth et Louis-Braille Visual impairment ... to see it well. [La déficience visuelle-Y voir clair.] Longueuil (Canada): Institut Nazareth et Louis-Braille; 2006.

101. Kelly-Evrard A. Blindness and independence [Cécité et autonomie.] Brussels (Belgium): I.M.P. du prince d'orange ASBL; 1996.

102. Pinto MR, De Medici S, Zlotnicki A, Bianchi A, Van Sant C, Napoli C. Reduced visual acuity in elderly people: The role of ergonomics and gerontechnology. Age Ageing. 1997; 26(5):339-44. [PMID: 9351477]

103. Aubot NG. ABCs of the activities of daily living [ABC des "Activités de la vie journalière"]. St. Gallen (France): Swiss National Association of and for the Blind [Verl. Des Schweizerischen Zentralvereins fur das Blindenwesen]; 1995.

104. Horowitz A, Reinhardt JP, Raykov T. Development and validation of a short-form adaptation of the age-related vision loss scale: The AVL12. J Vis Impair Blind. 2007; 101(3):146-59.

105. Dodds AG, Bailey P, Pearson A, Yates L. Psychologicalfactors in acquired visual impairment: The development of a scale of adjustment. J Vis Impair Blind. 1991;85(7): 306-10.

106. Horowitz A, Reinhardt JP. Development of the adaptation to age-related vision loss scale. J Vis Impair Blind. 1998; 92(1):30-41.

107. Dutil E, Bottari C, Vanier M. ADL profile assessment tool description [Profil des AVQ-Description de l'outil]. 4th ed. Montréal (Canada): Les Éditions Émersion; 2002. Available from: http://www.leseditionsemersion.com/

108. Silva-Smith AL, Theune TW, Spaid PE. Primary support persons for individuals who are visually impaired: Who they are and the support they provide. J Vis Impair Blind. 2007;101(2):113-18.

Submitted for publication October 5, 2007. Accepted in revised form April 7, 2008. 